\title{
Güvenlik Seviyesi Arttırılmış Akılı Otopark Sistemi
}

\author{
Ayșegül ÖZDEMIR ${ }^{1}$,Onur Özdal MENGi ${ }^{2 *}$ \\ ${ }^{1,2}$ Giresun Üniversitesi, Mühendislik Fakültesi, Elektrik Elektronik Mühendisliği, Giresun, Türkiye
}

*Sorumlu Yazar: onur.ozdal.mengi@giresun.edu.tr

Geliş Tarihi: 05.05 .2020

Kabul Tarihi: 05.06 .2020

\section{Öz}

Araçlarımızı park ettiğimiz otoparklar ne kadar güvenli? Yanına park ettiğimiz araç kime ait? Bu gibi sorulara cevap bulmak önemli bir problemdir. Bu sorulara cevap bulmak için, ortak yaşam alanlarında ve yüksek güvenlik gereken kamusal alanlarda akıllı otopark sistemi ihtiyacı doğmuştur. Bu nedenle araçları tanıyan, tanımadığı aracın içeri girmesine müsaade etmeyen ve park eden aracı adresleyen bir otopark tasarlanmıştır. Bu otoparkın girişinde araç kabulü için RFID (Radio Frequency Identification-Radyo Frekansı Tanımlama) teknolojisi kullanılmıştır. Bu teknoloji araçların kimliklerinin tanınması ve tanınan araçların kabulünü sağlamaktadır. Ayrıca geliştirilen akıllı otopark sisteminde, araçlar boş alanlara yönlendirilmekte, zaman kaybı azaltılmakta, insan müdahalesiz otopark yönetimi sağlanmaktadır. Araçlar otopark bölümlerine en küçük numaralı otopark bölümünden başlayarak kabul edilmektedir. Bariyer sistemlerinin kontrolü ve park alanlarının doluluk kontrolü için kızılötesi sensörler kullanılmaktadır. Bariyerlerin mekanik tahriki ise servo motorlarla sağlanmaktadır. Araç kabulü, bariyerlerin açılış sırası, yönlendirme ve servo motorların kontrolü mikro denetleyici tarafından yapılmaktadır. Böylece güvenilir ve ekonomik bir otopark sistemi ortaya konmuştur. Ayrıca bu sistemin değişik alanlarda da uygulanabilirliği için bir yol açılmıştır.

Anahtar Kelimeler: RFID, Güvenlik, Tanımlama, Kızı̈ötesi sensör, Mikro denetleyici.

\section{Smart Vehicle Parking System with Increased Security Level}

\begin{abstract}
How safe are the car parks? Who owns the vehicle we parked with? It is important to find answers to such questions. To find answers to these questions, there was a need for a smart parking system in communal areas and public spaces where high security is required. For this reason, a parking lot has been designed that recognizes vehicles, does not allow the vehicle that it does not recognize, and addresses the vehicle that parked. RFID (Radio Frequency Identification) technology is used for vehicle acceptance at the entrance of this parking lot. This technology ensures the identification of vehicles and the acceptance of recognized vehicles. Also, in smart parking system developed, vehicles are directed to empty spaces, time loss is reduced and parking management without human intervention is provided. Vehicles are accepted to the car park sections starting from the smallest car park section. Infrared sensors are used for the control of barrier systems and occupancy control of parking areas. The mechanical drive of the barriers is provided by servo motors. Vehicle acceptance, opening order of barriers, steering and control of servo motors are carried out by the microcontroller. Thus, a reliable and economical parking system has been introduced. In addition, a way has been opened for the applicability of this system in different areas.
\end{abstract}

Keywords: RFID, Security, Identification, Infrared sensor, Microcontroller. 


\section{Giriş}

1920 ve 1960 yılları arasında araç üretiminde artış meydana gelmesiyle otopark talebi artmış ve yeni bir sektör ortaya çıkmıştır (Eckermann, 2001). İnsanların araçlarını park ettikleri, özellikle hassas bölgeler ile meskenlerin bulunduğu yerlerdeki kapalı otoparkların güvenirliğinin yüksek olması artık temel bir ihtiyaçtır. Yakın bir zamana kadar bizzat insanlar tarafında takip edilen otoparkların yerini günümüzde nesnelerin haberleştiği, akıllı otoparkların alması bir ihtiyaç haline gelmiştir.

Günümüzde otoparkların dijital tekniklerle yönetimi ve denetimi gelişen teknolojiyle zorunlu hale gelmiştir. Çünkü teknoloji ile desteklenmiş otoparklar yönetim ve denetim açısından birçok kolaylık sağlamaktadır. Ayrıca çevreci çözümler sunması açısından da kayda değer bir öneme sahiptir. Dünyada ekonomik büyüme, motorlu araçlara olan ihtiyacın artmasına, hava kirliliğine, enerji ihtiyacının artmasına ve yaşam alanlarında meydana getirdiği olumsuz etkilere neden olmaktadır. Bu olumsuzlukları azaltmak için her türlü faaliyette olduğu gibi otoparklarda da ekonomik, tutarlı ve çevresel bir yönetimin geliştirilmesi gerekmektedir. Bu kapsamda yeni tip akıllı otopark sistemlerinde kabul edilecek araçların yönetici sistem tarafından tanınması ve kabul edilmesi maksadıyla çeşitli teknolojiler kullanılmaktadır. Araç kimliklerinin (Identification-ID) tanınmasında en geçerli yollardan birisi RFID okuyucu ve ID kart sistemidir.

RFID ilk olarak 1926 yılında askeri amaçlı kullanılmıştır (Want, 2006). II. Dünya Savaş1 esnasında RFID düşman uçaklarının belirlenmesinde önemli bir rol almıştır. RFID’in ilk ticari kullanımı ise 1984 yılında General Motors tarafından gerçekleştirilmiştir. General Motors'un otomobillerin gövdelerine yerleştirdiği RFID etiketler ile gövdede doğru donanımların kullanıldığını kontrol etmeyi amaçlamaktaydı. RFID ile 1970‘lerde nükleer malzeme izleme uygulamaları, 1990’larda ürün takip gibi ticari uygulamaları başlamıştır (Saatçioğlu, 2006).

Makalemizde anlatılan otopark sisteminde de araç kimliği tanımlamada RFID teknolojisi kullanılmıştır. Bu otopark sistemi, tanımadığı aracı kabul etmeyen, içeri giren ve tanımlanan aracı boş alanlara yönlendirebilen, park eden aracı adresleyerek üst düzey güvenlik tedbirlerine sahip bir akıllı otopark sistemidir.

Makalede anlatılan sistemin çalışması genel olarak; sistemde kayıtlı olan araçların tanımlı ID kartları veya etiketleri RFID okuyucu modülü tarafından okunur ve giriş bariyeri otomatik olarak açılır. ID tanımlaması olmayanlar kabul edilmez, otoparka girişi bariyer tarafından engellenir. Kabul edilen araçlar ana bariyeri geçtikten sonra, otopark alanlarından en küçük numaraya yönlendirme işlemi yapılır. Aynı zamanda otopark alanına araç giriş yaptı̆̆ı anda aracın ID numarası bilgisayarın ara yüzünden takip edilerek kaç aracın giriş yaptığı park alanı ve geriye ne kadar boş alanın kaldığı kayıt altına alınır. 
Eser, ortak yaşam ve yüksek güvenlik tedbirlerinin alınması gerekli güvenlik seviyesi yüksek alanlarda, güvenliği yükseltilmiş, zaman ve maddi kayıpları az, akıllı otopark sistemini geliştirerek uygulanabilirliğini ortaya koymaktır.

\section{Materyal ve Metot}

\subsection{RFID Teknolojisi ve Bileşenleri}

RFID teknolojisi, canlı ve cansız bütün nesnelerin Auto ID (Automatic Identification) numaraları içeren ve içerisine bütünleşmiş anten, tag (etiket) taşıyan nesne ile hareketlerinin temassız bir şekilde uzaktan izlenmesine, analiz edilip yönlendirilmesine olanak sağlayan teknolojidir. (Bhuptani ve Moradpour, 2005). Bütün bu işlemleri elektromanyetik tayf içerisindeki radyo dalgaları aralığında yapılmaktadır. Temel olarak tanımlanma ve veri toplamaya dayanan insan müdahalesiz bir teknolojidir. Şekil 1'de temel bileşenleri gösterilmiştir. Şekil 1'de gösterilmiş bileşenlerin çalışma prensibi kısaca şöyledir; RFID okuyucu taşıyıcı sinyal gönderir ve etiket tarafından modüle edilmiş sinyali algılar, etiket okuyucunun sinyalini alır ve etiket içindeki çip (yonga) sinyali modüle ederek okuyucuya gönderir.

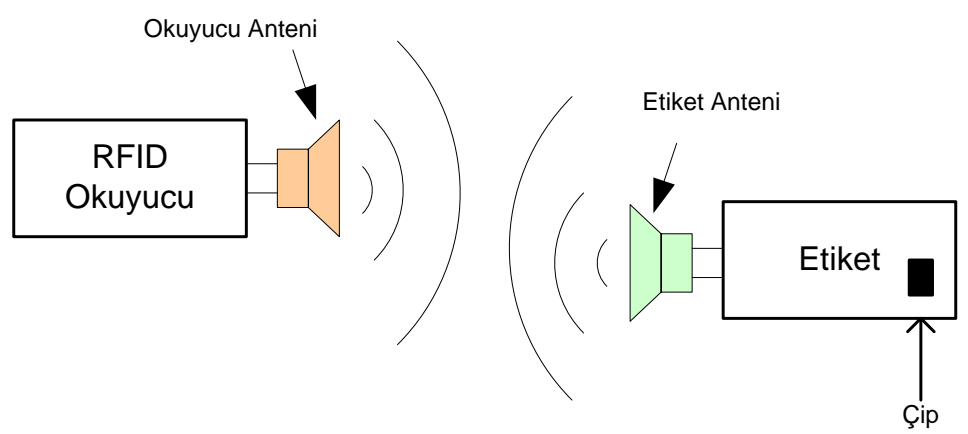

Şekil 1.RFID temel bileşenleri

RFID okuyucu ve etiket bu işlemi temassız bir şekilde yapmaktadır. Gözlemlenebilir bir yol gerekmez. Radyo frekansı ile yapılan bu işlem genel olarak etiket (transporter),okuyucu (alıcı-verici) ve alınan bilgilerin depolandığı veri tabanında gerçekleşmektedir. Okuyucular etikete enerji sağlar, taşıyıcı sinyali gönderir ve etiket tarafından modüle edilmiş sinyali algılar, şifresini çözer ve okur. RFID teknolojisini her alanda kullanabilir. RFID kullanmak hem zamandan hem de iş gücünden kazanmak istediğimiz durumlarda bize büyük bir avantaj sağlamaktadır. Başta güvenlik olmak üzere, personel takip sistemi, lojistik takip sistemi, mağaza yönetimi gibi sistemlerde RFID çözümlerine 
birer örnektir. RFID teknolojisi, günümüzde mobil ve kablosuz iletişim teknolojileri içerisinde kendisine önemli bir yer edinmiştir (Roberts 2006).

Etiketler ve okuyucular sistemin önemli bileşenlerindendir. Etiketler, bilgileri depolayan yonga ve okuyucu ile iletişime geçen bileşenlerdir. Etiketler ile yapılan denetlemeleri alır ve cevaplar. Sınırlı büyüklükte belleğe sahiptir. Etiketlerin 3 çeşit tipi bulunmaktadır. Bunlar pasif, yarı pasif ve aktif etiketlerdir (Chen ve ark., 2008).

Şekil 2'de etiketin içyapısı görülmektedir. İçinde bilgi barındıran mikroçip, anten ve kaplamadan oluşmaktadır. Nesneye ilişkin bilgileri depolar ve içerisinde bulunan anten radyo frekansını kullanarak nesneye ait bilgilerin okuyucuya gönderilmesini sağlar. Kaplama ise etiketin nesne üzerine yerleştirilebilmesi için mikroçip ve anteni çevreler. Etiketler kullanım yerlerine bağlı olarak değişik boyut ve fonksiyonda olabilmektedir (Syed ve Ilyas, 2008).

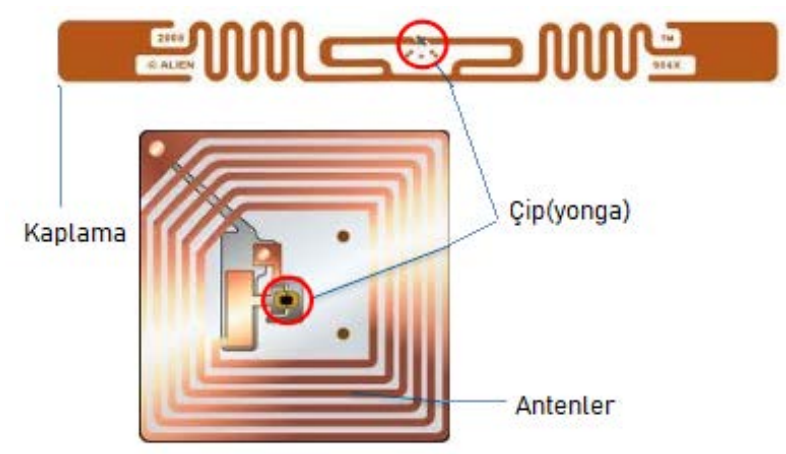

Şekil 2.Etiketin içyapısı

Şekil 3'de ki gibi etiketi bir kartın veya bir anahtarlığın içine yerleştirebiliriz. Yapıştırılabilir tip etiketler de araçlarda sıklıkla kullanılmaktadır.

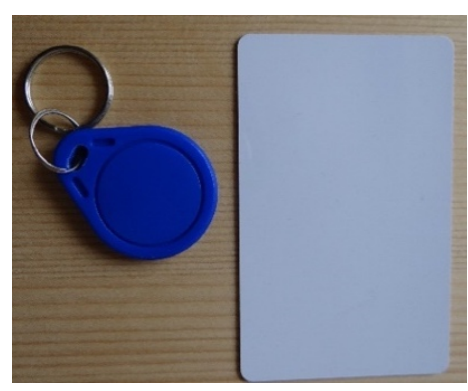

Şekil 3.Etiket taşıyıcı kart ve anahtarlık

Şekil 4'deki görüldüğü gibi okuyucu kartlara ihtiyaç bulunmaktadır. Şifreli olarak gelen veri okuyucu tarafindan algılanarak gerekli işlemler gerçekleştirilir (Roberts, 2006). 


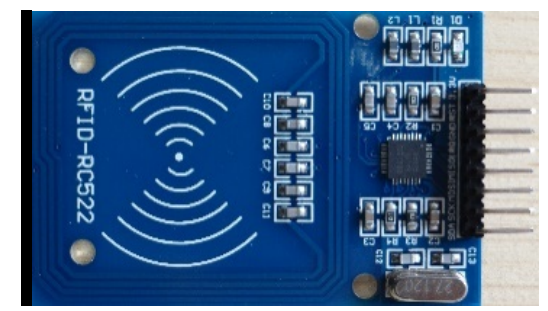

Şekil 4. RC522 RFID okuyucu modülü

\subsection{RFID'de Güç Aktarımı}

RFID etiketi, her ikisi de karmaşık empedanslara sahip bir anten ve bir çip (yonga) içerir. Çip, iletilen RFID okuyucu adı verilen radyo frekansı sinyalinden güç alır. RFID etiket anteni, empedansı genellikle yüksek ve düşük olmak üzere iki empedans durumu arasında değişen çip ile yüklenir. Her yük durumunda, RFID etiketi belirli bir radar kesiti (RCS) sunar. Şekil 5'de RFID ile güç aktarımı görülmektedir. Burada etiket, bilgilerini değiştirerek bilgileri geri gönderir ve böylece geri saçılmış sinyalin modüle edilmesi sağlanır.

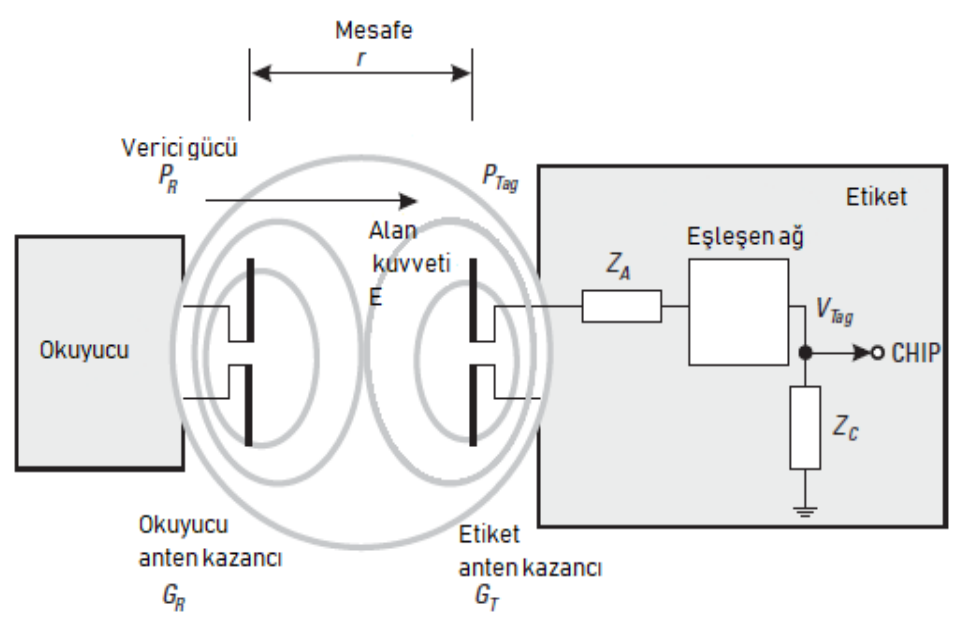

Şekil 5. İleri güç aktarımı eşdeğer devresi

Şekil 5'de görülen etiket içerisindeki empedanslar $\mathrm{Z}_{\mathrm{A}}=\mathrm{R}_{\mathrm{A}}+\mathrm{j} \mathrm{X}_{\mathrm{A}}(\Omega)$ karmaşık anten empedans1, $\left.\mathrm{Z}_{\mathrm{C}}=\mathrm{R}_{\mathrm{C}}+\mathrm{j} \mathrm{X}_{\mathrm{C}}\right)(\Omega)$ karmaşık yonga (yük) empedansıdır. Çip empedansı, frekans ve giriş gücüne göre değişir. Antenler arasındaki mesafe ' $r$ ', etiketin okuyucunun uzak alanında olması için yeterince büyük olduğu varsayılan mesafedir. E, etiket yerinde okuyucunun elektrik alan gücüdür. (ağdaki kayıplar $\mathrm{G}_{\mathrm{T}}$ değerinde de açıklanabilir). Petiket (tag) gücü Şekil 5 'teki eşdeğer devre göz önüne alındığında Denklem 1'deki formül elde edilir.

P etiket $=\left(E^{2} / 120 \pi\right)\left(\lambda^{2} / 4 \pi\right) \cdot G_{T}$ 
Denklem1 'de, P etiket = Etiket Gücü $(\mathrm{dBm}), \mathrm{E}=$ Elektrik Alanı $(\mathrm{V} / \mathrm{m}), \lambda=\operatorname{dalga}$ boyu $(\mathrm{m}), \mathrm{G}_{\mathrm{T}}=$ Etiket anten kazancı (dB), $\pi$ sabit değer (22/7). Denklem 1'deki formülü en kısa haliyle etiket voltajının $\left(\mathrm{V}_{\text {tag }}\right)$ karesini $\left(\mathrm{V}_{\text {etiket }}\right)^{2}$ yukarıda belirttiğimiz yonga omik direnci $\left(\mathrm{R}_{\mathrm{c}}\right)$ ' ye bölerek de bulabiliriz.

P etiket $=\left(V_{\text {etiket }}\right)^{2} / R_{c}$

Denklem 2'de, $\quad \mathrm{P}$ etiket $(\mathrm{W}) \mathrm{V}_{\text {etiket }}\left(\mathrm{V}_{\text {tag }}\right)=$ Etiket gerilimi $(\mathrm{V}),. \mathrm{R}_{\mathrm{c}}=$ Çip omik direncini $(\Omega)$ ifade etmektedir.

$E^{2} / 120 \pi=P_{R} G_{R} / 4 \pi r^{2}$

Denklem 3'de, $\quad P_{R}=$ Verici gücü $(d B m),. G_{R}=$ Okuyucu anten kazancı $(d B), r=$ Antenler arası mesafe (m). Bu denklemleri düzenlediğimizde Denklem 4 elde edilir:

P etiket $=P_{R} G_{R} G_{T} \lambda^{2} /(4 \pi)^{2} r^{2}$

Denklem 4'de; P etiket = Etiket Gücü $(\mathrm{dBm}), \mathrm{G}_{\mathrm{R}}=$ Okuyucu anten kazancı $(\mathrm{dB}), \mathrm{G}_{\mathrm{T}}=$ Etiket anten kazanc1 (dB), $\lambda=$ dalga boyu(m), $\pi$ sabit değer(22/7), $r=$ Antenler arası mesafe $(\mathrm{m})$.

Tipik maksimum okuyucu çıkış gücü $500 \mathrm{~mW}, 2 \mathrm{~W}$ (ERP, CEPT) ve 4W (EIRP, FCC). DBm 'ye dönüştürülürse, izin verilen maksimum sınırlar yaklaşık 29 dBm (500 mW ERP, 825 mW EIRP), $35 \mathrm{dBm}$ (2W ERP, 3.3W EIRP) ve $36 \mathrm{dBm}$ 'dir (4W EIRP). Alınan gerilim $V_{\text {etiket }}$ i düzeltilebilecek kadar büyük olmalıdır ve etiketi güçlendirmek 1,2 Vrms'yi aşan bir gerilim gerektirebilir. Rc'nin

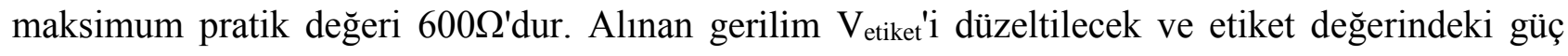
değerinden büyük olmalıdır; 1,2 Vrms'yi aşan bir gerilim gerekebilir ( Harwey, 2008).

Şekil 6'da giriş etiket gücü ile antenler arası mesafenin değişim grafikleri görülmektedir. Güç arttığında etkin yayın gücünün yükseldiği, buna karşın mesafe arttıkça azaldığı takip edilebilir. 


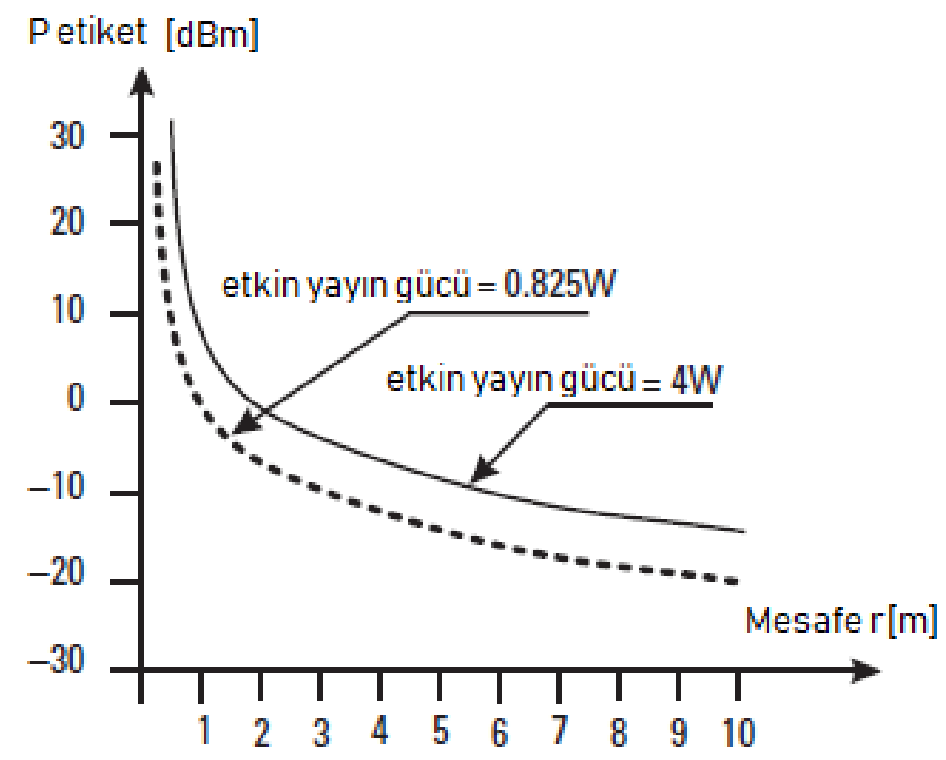

Şekil 6. Mesafeye karşı etiketten alınan güç

\subsection{Yakın Alan Yayılım Sistemleri}

Düşük ile orta RFID frekanslarında, RFID sistemleri yakın alan iletişimini ve manyetik alandan endüktif kuplajın fiziksel özelliğini kullanır. Şekil 7' de görüldüğü gibi okuyucu ve etiket arasında manyetik bir alan oluşturur. Etiketin anteninde, tümleşik enerjiye güç sağlamak için kullanılan bir gerilim indüklenir ve elektrik akımı oluşur. Etiket, antenindeki yükü değiştiğinde, okuyucunun iletişim bobinine çekilen akım da değişerek okuyucuya geri iletilir.

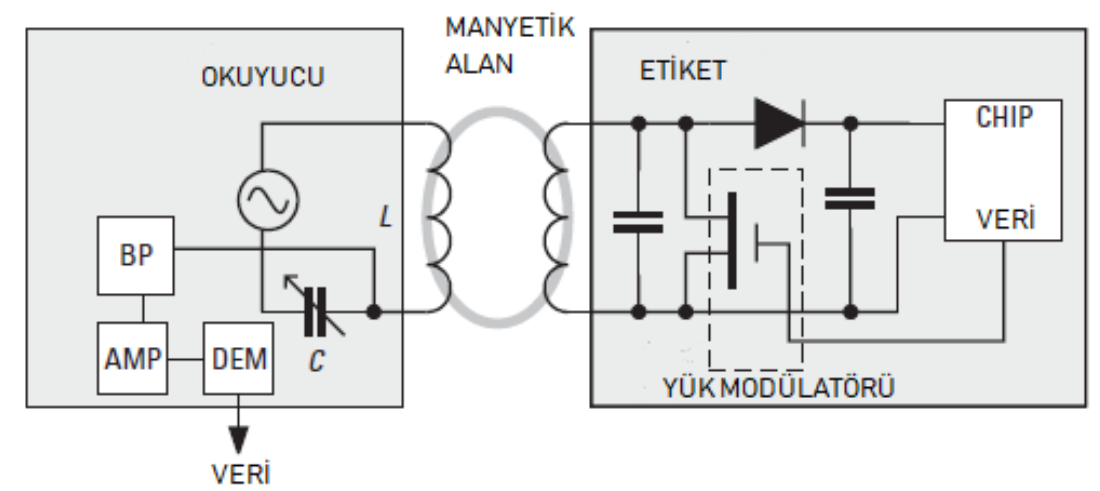

Şekil 7.Okuyucu ile etiket arasındaki yakın alan yayılım sistemi

Etiketin okuyucu alanından verimli bir şekilde enerji çekebilmesi, elektrik rezonans etkisine dayanır. Etiketin kuplajı veya anten elemanı gerçekten bir endüktör bobini ve birbirine bağl1 13.56 MHz sistem çalışma frekansında rezonansa gelecek şekilde tasarlanmış kapasitördür. İndüktörden geçen akım Amper yasasına göre çevreleyen bir manyetik alan oluşturur.

Şekil 8'de manyetik alan etkisinin olduğu A noktası ve manyetik alanın uzaklığa göre değişim eğrisi de göz önüne alınırsa; Kaynaktan $r>>$ a ile uzaklaştıkça, basitleştirilmiş karakteristik $1 / \mathrm{r}^{3}$ 
zayıflamasını gösterir. Manyetik alanın bu yakın alan bozulma davranışı, bir RFID cihazının okuma aralığındaki ana sınırlayıcı faktördür.

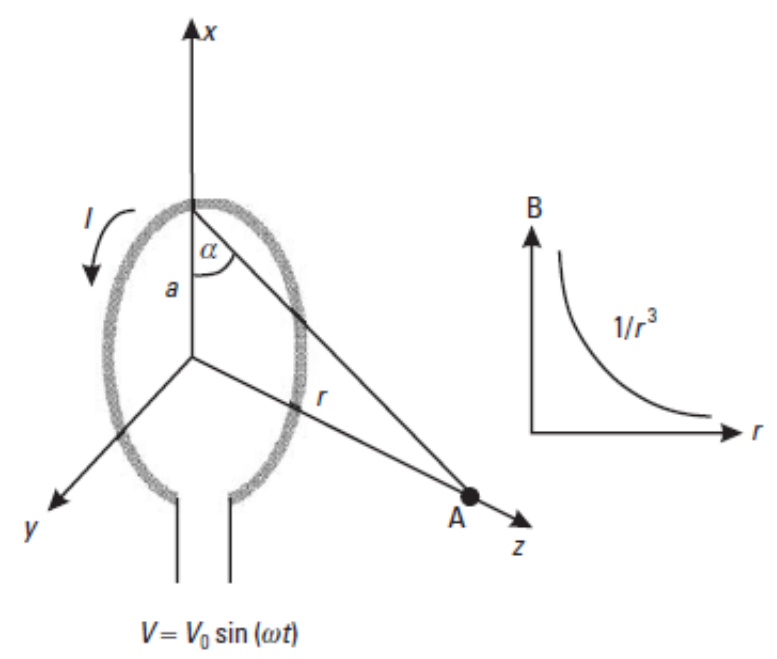

Şekil 8. Manyetik alanın bobinden uzağa hesaplanması

Endüktif kuplaj prensibinden,

$\mathrm{B}=\frac{\mu_{0} \mathrm{IN} \mathrm{a}}{2 \mathrm{r}^{3}} \quad\left[\right.$ Weber $\left./ \mathrm{m}^{2}\right]$ veya tesla

Denklem 5'de, B= Manyetik Alan Şiddeti (Tesla), I= bobin boyunca akım (A), N=bobin içindeki sargı sayısı, a=bobin yarıçapı $(\mathrm{mm}), \mu_{0}=$ manyetik geçirgenlik $\left(4 \pi \times 10^{-7} \mathrm{H} / \mathrm{m}\right), r$ =antenden noktaya dik mesafe (m)’yi göstermektedir.

Ohm yasası kullanırsak:

$\mathrm{I}=\frac{\mathrm{V}}{\mathrm{ZL}}=\frac{\mathrm{V}}{\omega \mathrm{L}}$

Denklem 6'da, I= Bobin akımı (A), V=bobin gerilimi (V), ZL=Bobin empedansı ( $\Omega$ ), L=Bobin Endüktansı $(\mathrm{H})$ ifade etmektedir. L’nin aşağıdaki gibi tahmin edilebileceğini varsayılır:

$\mathrm{L} \approx \mu_{\mathrm{o}} \pi \mathrm{a} \mathrm{N} \mathrm{N}^{2}$

Denklem 7'de, L=bobin Endüktansı $(\mathrm{H}), \mu_{\mathrm{o}}=$ manyetik geçirgenlik $\left(4 \pi \times 10^{-} 7 \mathrm{H} / \mathrm{m}\right)$, N=bobin içindeki sargı sayısı(sipir), a=bobin yarıçapı (mm)'dir. Denklem 5’i tekrar yazarsak:

$B=\frac{V}{2 \omega \mathrm{N} \pi \mathrm{r}^{3}}$ 
Son denklemde, $\mathrm{B}=$ Manyetik alan şiddeti (Tesla), $\mathrm{V}=$ Bobin gerilimi (Volt), N=Bobin içindeki sarg1 sayısı, $\mathrm{r}$ =antenden noktaya dik mesafe $(\mathrm{m})$.

Bobinden belirli bir mesafede belirli bir bobin voltajı ile (8) 'den itibaren, B'nin N ile ters orantılı olduğunu görebiliriz. Bunun nedeni, akımın belirli bir bobin voltajı ile $1 / \mathrm{N}^{2}$ oranında artmasıdır.

Manyetik alanı en üst düzeye çıkarmak için, sabit anten boyutları verildiğinde, antene verilen akımın en üst düzeye çıkarılması gerektiğini belirtir. Ek olarak, akımı en üst düzeye çıkarmak için anten, okuyucu devresi tarafindan sağlanan uyarma frekansında rezonansa girmelidir. Okuyucunun rezonans frekansı ( $\mathrm{f}_{0}$ ) antenin endüktansı (L) tarafından belirlenir (okuyucunun yarıçapı ile belirlenir) bobin, sargı sayısı, sargıların kalınlığı ve bobinin uzunluğu) ve bir ayarlama kapasitörü (C) aşağıdaki gibi hesaplanır.

$f o=1 / 2 \pi \sqrt{L C}$

Denklem 9'da, fo = Rezonans frekansı (Tesla), L=Bobin endüktansı (H), C=Kondansatör kapasitansı $(\mu \mathrm{F})$ 'nı ifade etmektedir.

\subsection{Anten Devrelerinde Verilen Gerilimler}

Faraday yasası, kapalı bir yolla sınırlanmış bir yüzeyde zamanla değişen bir manyetik alanın döngü etrafında bir voltaj indüklediğini belirtir. Şekil 9, bir RFID uygulaması için basit bir yap1 göstermektedir. Etiket ve okuyucu antenleri yakın olduğunda, bir okuyucu anten bobini tarafindan üretilen zamanla değişen manyetik alan $\mathrm{B}$, kapalı etiket anten bobininde bir voltaj (elektromotor kuvvet veya sadece EMF olarak adlandırılır) indükler.

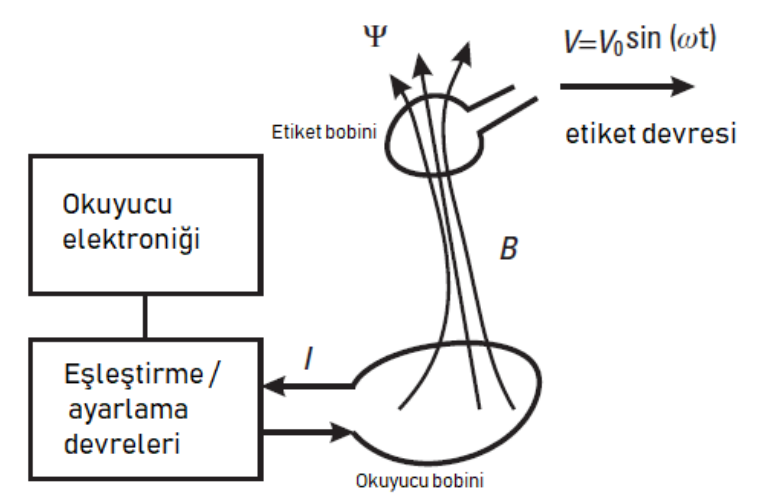

Şekil 9. Temel okuyucu ve etiket yapılandırması 
Bobin içindeki indüklenen voltaj, bobin üzerinde bir akım akışına neden olur. Etiket anten bobinindeki indüklenen gerilim manyetik akının zamana göre akı değişiminin anten bobini sipir sayısı ile çarpımına eşittir. Denklem 10'daki negatif işaret, indüklenen voltajın, onu üreten manyetik akıya karşı koyacak şekilde davrandığını gösterir. Bu” Lenz Kanunu” olarak bilinir ve devredeki akım yönünün, indüklem akım tarafından üretilen manyetik alanın kendini oluşturan manyetik alana karşı çıkacağını vurgular.

$V=-N \frac{d \Psi}{d t}$

Denklem 10'da, V= İndüklenen gerilim (V), N= anten bobinindeki sipir sayısı; $d \psi=$ manyetik akıdaki değişim, $\mathrm{dt}=$ zamandaki değişimi göstermektedir.

Anten bobininin tüm yüzeyinden geçen toplam manyetik alan ve şu şekilde bulunur:

$\Psi=\int \mathrm{B} \cdot \mathrm{dS}$

Denklem 11'de, $\Psi=$ toplam manyetik akı (maxwell) B = manyetik alan şiddeti (Tesla), $\mathrm{S}=$ bobinin yüzey alanı $\left(\mathrm{mm}^{2}\right), \bullet=$ vektörlerinin iç çarpımı (iki vektör arasındaki kosinüs açısı)'dır.

Yüzey alanı S Hem manyetik alan B hem de yüzey S vektör miktarlarıdır. İki vektörün iç çarpımının sunulması, anten bobininden geçen toplam manyetik akının $\Psi$ anten bobinlerinin yönünden etkilendiğini düşündürmektedir. İki vektörün iç çarpımı, ikisi arasındaki kosinüs açısı $90^{\circ}$ olduğunda veya iki (B alanı ve bobinin yüzeyi) birbirine dik olduğunda kosinüs açısı $0^{\circ}$ olduğunda minimize edilir. Etiket bobininden geçen maksimum manyetik akı iki bobin (okuyucu bobin ve etiket bobin) birbirine paralel olarak yerleştirildiğinde elde edilir. Bu durum, etiket bobininde maksimum indüklenen voltaj ve ayrıca maksimum okuma aralığı ile sonuçlanır. Okuyucu ve etiket bobinleri arasındaki karşılıklı birleşme açısından da ifade edilebilir. Şimdiye kadar verilen ifadeleri birleştirerek, rezonans frekansında etiket anteni üzerindeki voltaj aşağıdaki Denklem 12'deki olduğu gibi hesaplanabilir:

$\mathrm{V}_{\text {etiket }}=2 \pi \mathrm{fN}$ Q B S $\cos (\alpha)$

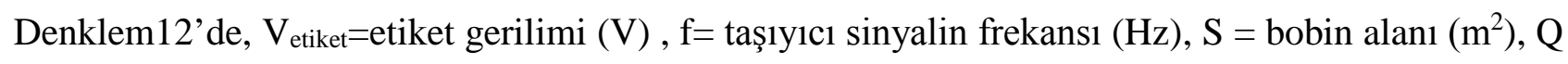
= rezonans devresinin kalite faktörü, $\alpha=$ etiket alanına normal alanın açısı ifade etmektedir.

(Harwey, 2008). 


\subsection{Kızılötesi (InfraRed-IR ) Sensör Teknolojisi}

Kızılötesi (InfraRed-IR) sensör, çevrenin bazı özelliklerini algılamak için yayan elektronik bir cihazdır. Kızılötesi sensör bir nesnenin hareketini tespit edebilir. Bu tür sensörler pasif kızılötesi sensör olarak adlandırılan yaymak yerine sadece kızı̈ötesi radyasyonu ölçer. Genellikle kızılötesi spektrumda, tüm nesneler bir tür termal radyasyon yayar. Bu tip radyasyonlar, kızılötesi bir sensör tarafından tespit edilebilen fakat gözlerimiz için görünmezdir. Kızılötesi engel algılayıcılar genelde kızılötesi LED ve bunun yaydığı kızılötesi 1şığın üzerine düştüğünde direnci veya çıkış voltajı değişen foto eleman çiftidir.

Kızılötesi spektrumunun çeşitli bölgelerinde çalışan farklı kızılötesi sensörler üç fizik yasası ile açıklanır.

- Planck'in Radyasyon Kanunu

- Stephan Boltzmann Yasas1

- Wein Yer Değiştirme Kanunu

\subsubsection{Kızılötesi Engel Sensörü Yansıma Prensibi}

Kızılötesi engel sensörü bir IR LED'i ve bir IR foto diyottan oluşur ve optokuplör olarak adlandırılırlar. Şekil 10’da bu tip bir sensörün çalışma prensip şeması görülmektedir.

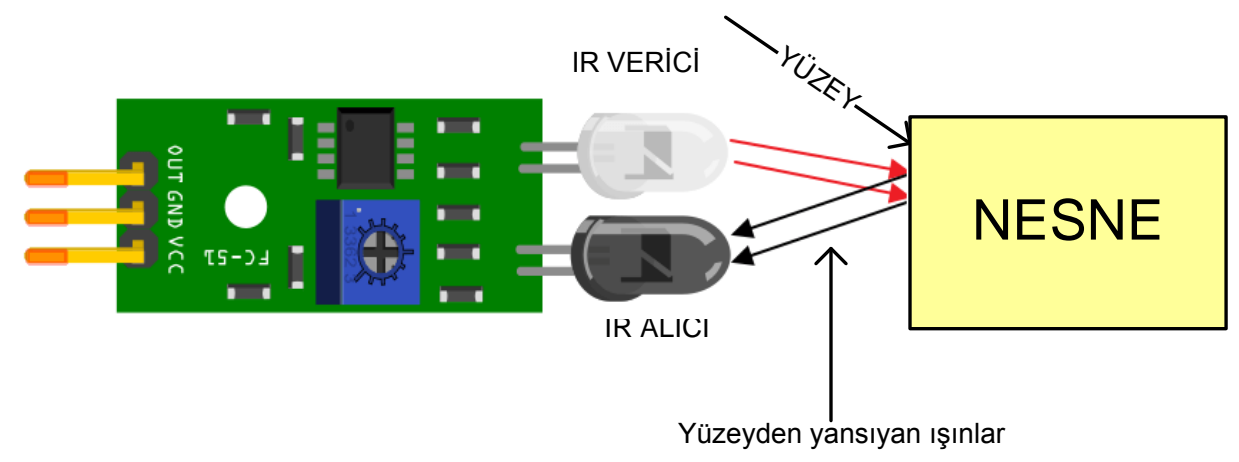

Şekil 10.Kız1l ötesi engel sensörü çalışma prensibi

Şekil 10'da görüldüğü gibi; IR verici LED kızılötesi 1şık yaydığında, nesneye ulaşır ve kızılötesi 1şığın bir kısmını IR alıcısına geri yansıtır. IR alıcısı tarafından geri dönen kızılötesi 1ş1k yoğunluğuna bağlı olarak, sensörün çıkış gerilimi değişir. Değişen gerilim NPN veya PNP bir transistör iletime veya yalıtıma geçirerek sensörün (OUT) ucu gerilimini pozitif çalışma gerilimi verecek şekilde veya 
$0 \mathrm{~V}$ yapar. Ĕger verici ve alıcı karşısına herhangi bir nesne yaklaşmaz ise vericinin gönderdiği kızılötesi 1şık alıcıya ulaşamayacağından alıcı foto eleman uçlarında herhangi bir direnç veya gerilim değişimi yaşanmaz.

\subsubsection{Engel Algılama Devresi veya IR Sensör Devresi}

Kızılötesi sensör devresi, bir elektronik cihazdaki temel sensör modüllerinden biridir. $\mathrm{Bu}$ sensör, engelleri tespit etmek için kullanılabilen insanın duyularına benzer ve gerçek zamanlı olarak yaygın uygulamalardan biridir. Bu devre yukardaki Şekil 11'deki bileşenlerden oluşur. Bir kızılötesi LED, bir foto diyot, bir potansiyometre, bir amplifikatör ve bir LED'den oluşur. Kızılötesi LED kızılötesi 1şık yayar. Foto diyot kızılötesi 1şığı algılar. Bir amplifikatör gerilim karşılaştırıcı olarak kullanılır. Potansiyometre, sensörün çıkışını ihtiyaca göre kalibre etmek için kullanılır.

Kızılötesi LED tarafından yayılan ışık bir nesneye vurulduktan sonra foto diyotta meydana geldiğinde, foto diyotun direnci büyük bir değerden düşer. Operatör girişlerinden biri potansiyometre tarafından belirlenen eşik değerdedir. Olay radyasyonu foto diyotta daha fazla olduğunda, seri direnç üzerindeki gerilim düşüşü yüksek olacaktır.

Kızılötesi alıcısı bir sinyal almadığında, evirici girişindeki potansiyel, karşılaştırıcı LM358 evirmeyen girişinden daha yüksek olur. Böylece karşılaştırıcının çıkışı azalır, ancak LED yanmaz. Kızılötesi alıcı modülü, evirici girişindeki sinyal aldığında azalır. Böylece karşılaştırıcının LM 358 çıkışı yükselir ve LED yanmaya başlar. Direnç $\mathrm{R}_{1} 150 \Omega, \mathrm{R}_{2} 10 \mathrm{k} \Omega$ ve $\mathrm{R}_{3} 22 \Omega$, minimum $10 \mathrm{~mA}$ akımın IR LED Cihazlarından geçmesini sağlamak için kullanılır. Foto diyot ve normal LED'ler. Direnç VR (ön ayar = 10k $\Omega$ ) çıkış terminallerini ayarlamak için kullanılır (JHA, 2000).

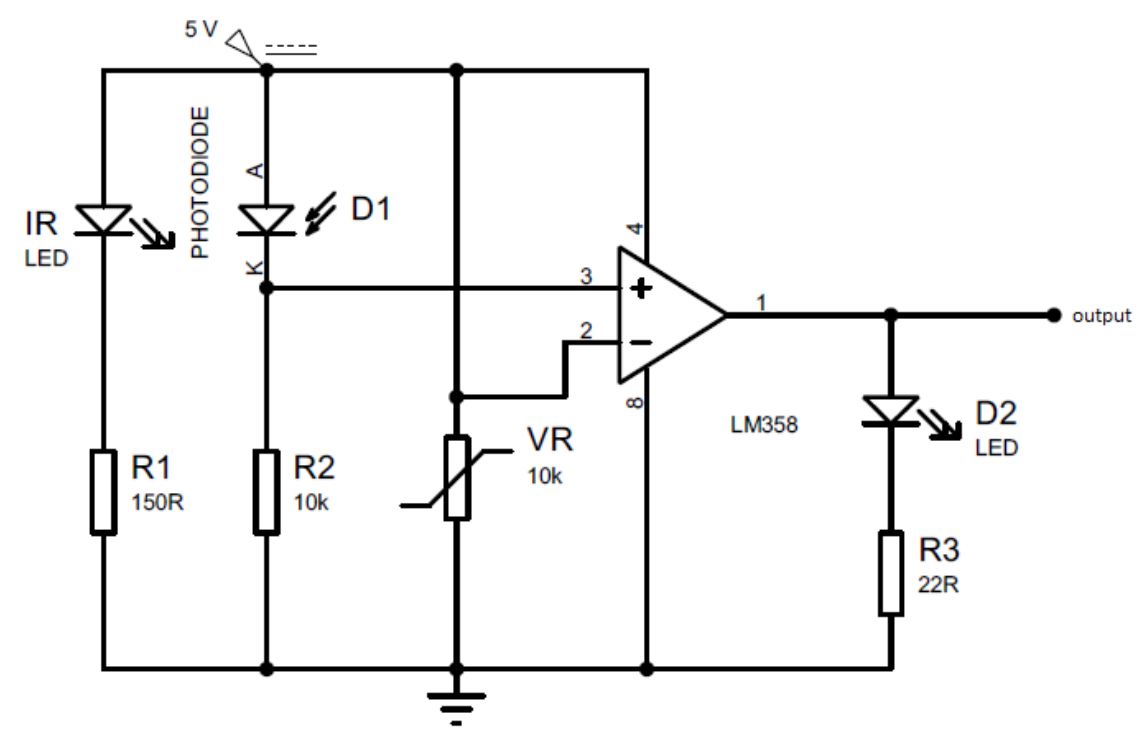

Şekil 11. Kızıl ötesi engel sensörü devresi 


\subsection{Servo Motor Teknolojisi}

Servo motorlar, kontrol sistemlerinde sınırlandırılmış hareket sağlayan motorlardır. Güç değerleri endüksiyon motorlarından düşüktür. Dolayısıyla ataletleri de düşüktür. Çapları endüksiyon motorlarına nazaran küçüktür. Düşük hızda veya belirli bir açı kadar dönecek şekilde çalışırlar ve bu sebeple momentleri adı motorlarına nazaran daha yüksektir. Robotlar, otomasyon sistemiyle çalışan tezgâhlar, anten tahrik sistemleri, gibi çeşitli yerlerde kullanılabilirler. DC ve AC tipleri vardır. Şekil 12'de servo motor ve bağlantı pinleri görülmektedir.

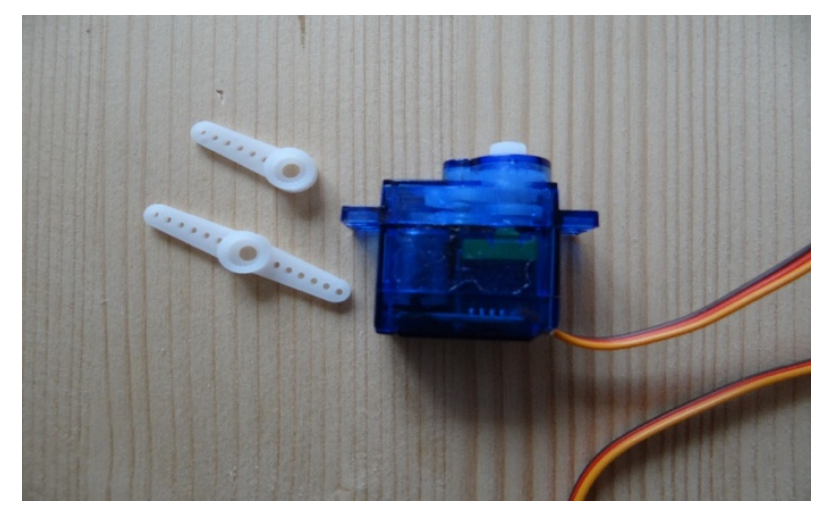

Şekil 12.Servo motor ve bağlantı pinleri(SG 90)

Servo motorların kontrolü için PWM (sinyal genişlik modülasyonu) kullanılır. Motor'un girişine gelen PWM sinyali görev çevrimine göre motor pozisyon değiştirmektedir. Şekil 13’te görülen servo motor açısal pozisyonlarının değişimi görülmektedir. Toplam çalışma süresi 20 ms ‘dir. $1 \mathrm{~ms}$ 'de 0 derece, $1.25 \mathrm{~ms}$ de, $1.5 \mathrm{~ms}$ 'de 90 dereceye ve $2 \mathrm{~ms}$ 'de 180 dereceye gelmiş olur.2ms'de görev çevrimini tamamlamış olur. (Sen, 2012) 


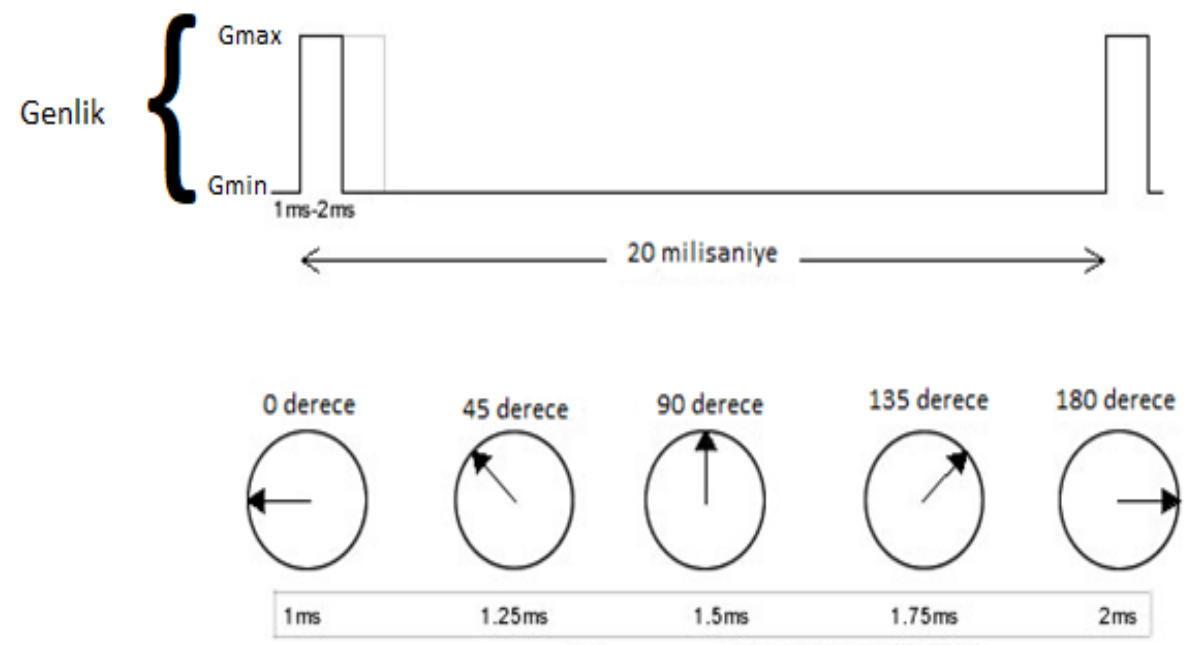

Şekil 13. PWM darbe genişliği modülasyonu

$G=\frac{1}{T} \int_{0}^{T} f(t) d t$

$\mathrm{G}=\frac{1}{T}\left(\int_{0}^{D T} G \max d t+\int_{D T}^{T} G \min d t\right)$

Denklem 13 ve 14'de, üretilen kare dalganın genlik değerini kare dalganın frekansı $f(t)=$ zamana bağlı fonksiyon olarak belirlersek,G min=en düşük genlik değeri, Gmax= en yüksek genlik değeri, $\mathrm{D}=$ (duty cycle )görev döngüsü, $\mathrm{T}=$ Darbe genişlik modülasyonu periyodudur.

\subsection{Arduino Teknolojisi}

Arduino bir I/O (giriş/çıkış) kartı ve Processing/Wiring dilinin bir uygulamasını içeren geliştirme ortamını oluşturan bir fiziksel programlama platformudur. Mikro denetleyici komutları bekleyen küçük bir komuta merkezidir. Birkaç satır kodla 1şık açıp kapayabilir, bir sensör değerini okuyabilir veya bilgisayar ekranımızda görüntüleyebiliriz. Arduino IDE ise mikro denetleyiciler için entegre geliştirme ortamıdır. $\mathrm{C}$ ve $\mathrm{C}++$ dilleri kullanılarak yazılım oluşturulabilir. Bu uygulama sayesinde günlük hayata kolaylık getirebilecek projeler yapabiliriz (Warren ve arl., 2014).

Akıllı otopark sisteminde birden fazla sensör ve bileşen kullandığımız için uygun olarak Şekil 14 'de gördüğümüz Arduino Mega 2560 mikro denetleyici kullanılmıştır. 


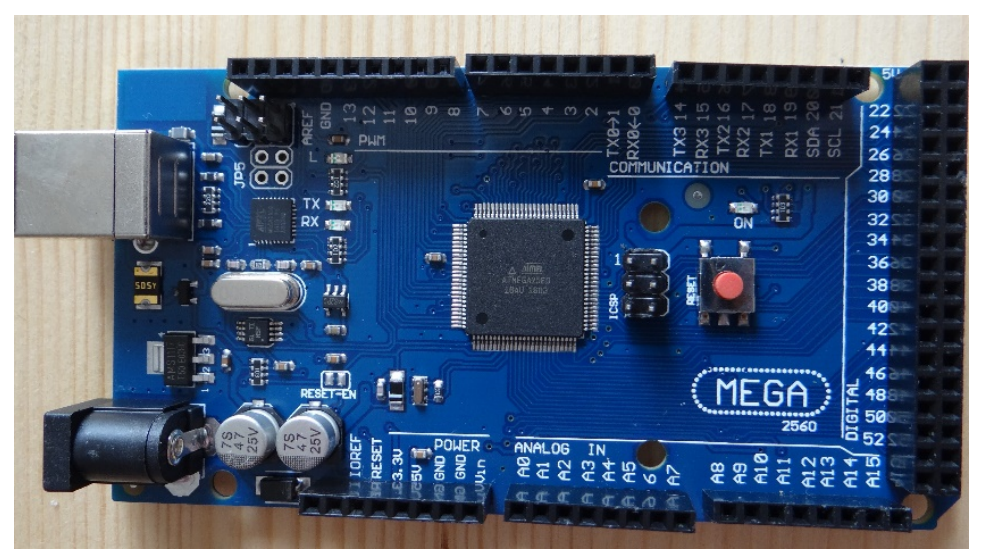

Şekil 14.Arduino Mega 2560

\subsection{Sistemin Yapısı ve Çalışma Prensibi}

Otopark daha önceden veri tabanına tanımlanmış araçlar için giriş bariyerini açmaktadır. Tanımlama işinde araçlara yerleştirilmiş ve plakası ile eşleştirilmiş RFID kartlar kullanılmaktadır. 9 adet otopark alanı bulunmaktadır. Tanınmış aracın yönlendirilmesi ise, boş olan ve en küçük numara verilmiş otoparka yapılmaktadır. Bariyerlerin açılış sırası ve yönlendirme yazılım ile sağlanmaktadır. Ayrıca park eden her aracı adresleyerek hangi aracın nerede olduğu takip edilebilmektedir.

Araçların üzerinde araçların kodunu içeren RFID kartlar bulunmaktadır. Sistem başlangıçta iken tüm bariyerler kapalı, boş otoparkların üstünde yeşil LED lambalar, dolu otopark bölümlerinin üstünde kırmızı LED lambalar yanmaktadır.

Tanımlanmış araç ana kapıya gelince araç üzerinde bulunan kart RFID okuyucu tarafindan okunacak eğer araç sisteme tanıtılmış ve geçiş izni varsa ana bariyer ana servo tarafindan açılacak. Araç 1. kızılötesi sensörü geçtiğinde ana bariyer kapanıp 1. otopark boşsa 1. otopark bariyeri 1 nolu servo tarafından açılacak. Bu bariyer ile birlikte 1 nolu yön levhası yanacak. Araç yerine yerleşince 1. Otopark bariyeri 1 nolu sensör tarafından kapatılacak. Aracın yerleştiği bilgisi sistem tarafindan kayıt edilecek ve aracın yerleştiği otopark bölümünün kırmızı LED lambası yanıp yeşil LED lambası sönecek. Eğer 1. Otopark doluysa ana bariyer kapandığında 2 nolu otopark bariyeri 2 nolu servo tarafından açılacak. Bu bariyerin açılması ile birlikte 2 nolu yön levhası yanacak. Araç yerine yerleşince 2. Otopark bariyeri 2 nolu sensör tarafından kapatılacak.

Aracın yerleştiği bilgisi sistem tarafından kayıt edilecek ve aracın yerleştiği otopark bölümünün kırmızı led lambası yanıp yeşil led lambası sönecek. Eğer 2. Otopark doluysa ana bariyer kapandığında 3 nolu otopark bariyeri 3 nolu servo tarafindan açılacak. Bu bariyerin açılması ile birlikte 3 nolu yön levhası yanacak. Araç yerine yerleşince 3. Otopark bariyeri 3 nolu sensör tarafından kapatılacak. Aracın yerleştiği bilgisi sistem tarafından kayıt edilecek ve aracın yerleştiği otopark bölümünün kırmızı led lambası yanıp yeşil led lambası sönecek. Bir araç çıkış yaparsa ilk 
gelecek araç en küçük numaralı otoparktan itibaren yerleşecektir. Tüm otoparklar dolduğunda tanınan bir araç gelse dahi ana bariyer açılmayacaktır.

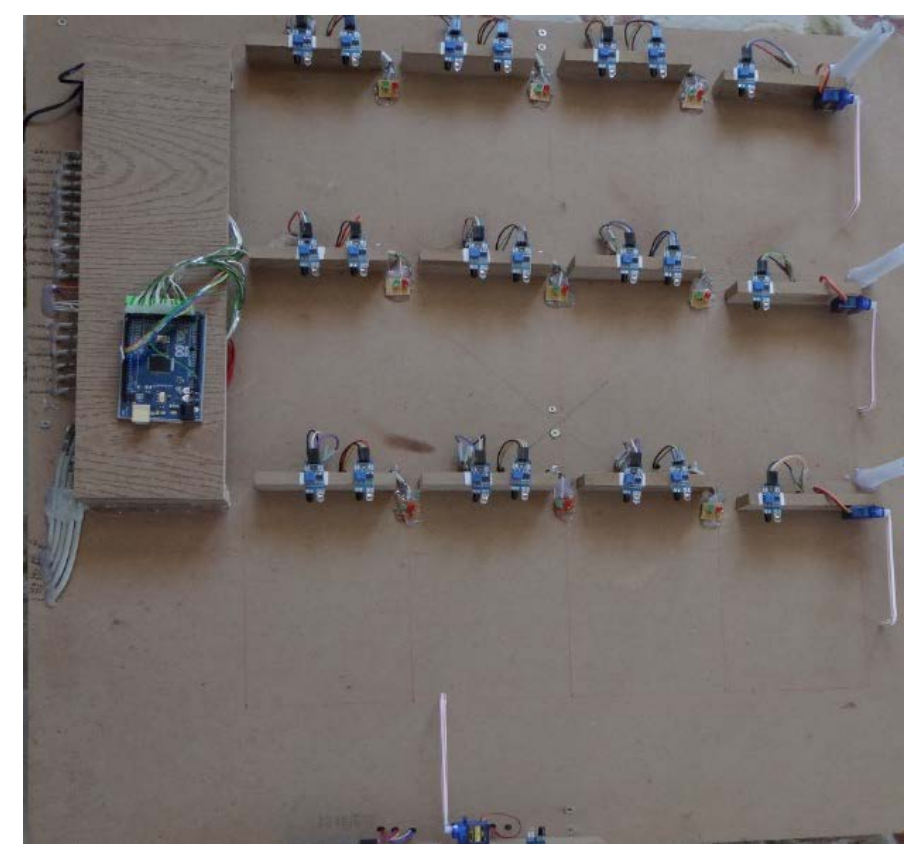

Şekil 15.Akı1lı otopark modeli

Şekil 15’de Proteus ISIS programında sistemin eş değer devresi çıkarılarak yazılan kodun doğru çalıştığını kontrol etmek için yapılan benzetim çalışması görülmektedir.

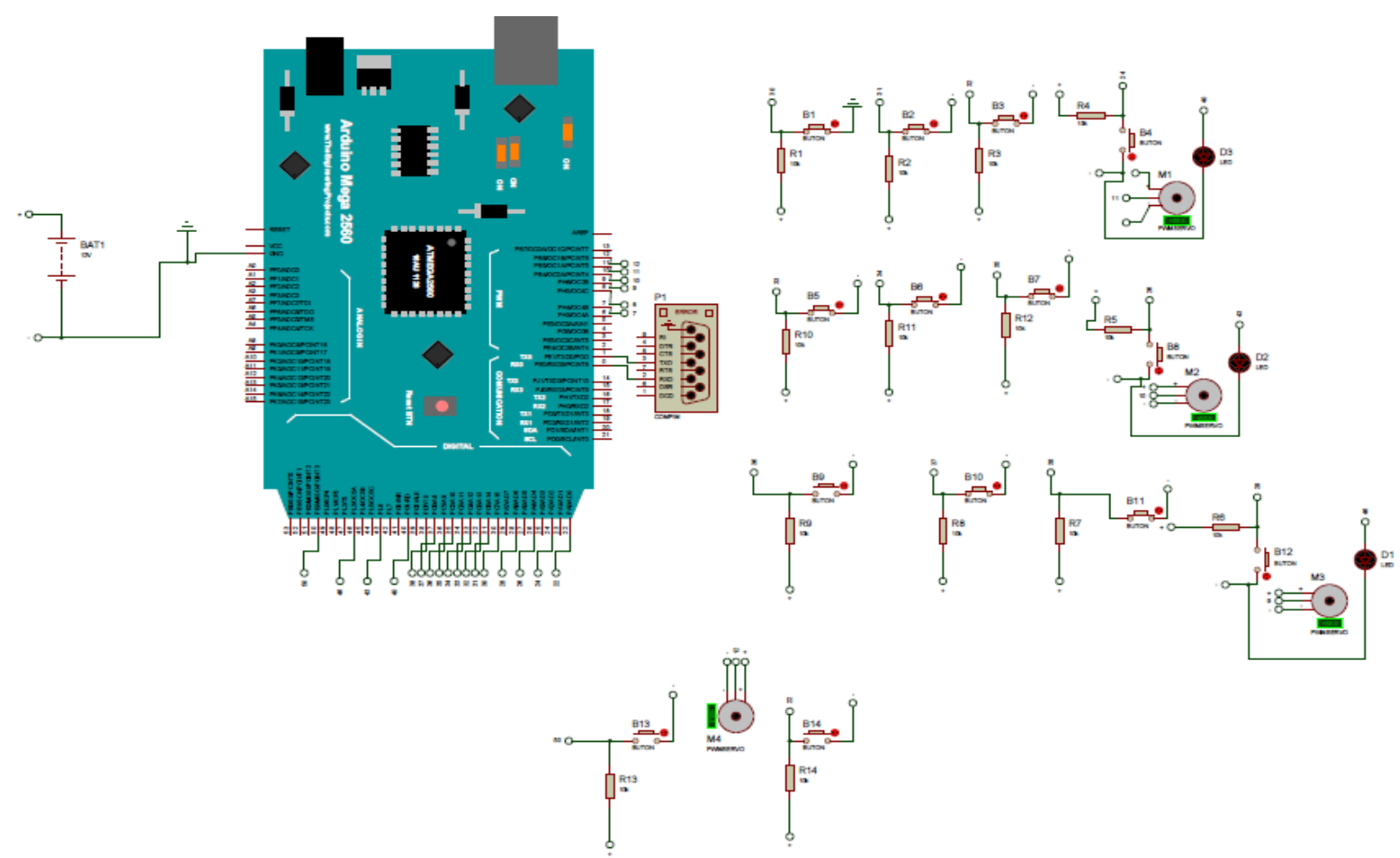

Şekil 16. Akıllı otopark sisteminin ISIS programındaki simülasyon şeması 
C\# programlama dili ile yazılan ara yüz ile hangi otopark alanının dolu olup hangi alanın boş olduğu takip edilmektedir. Şekil 17’de sistem görülmektedir.

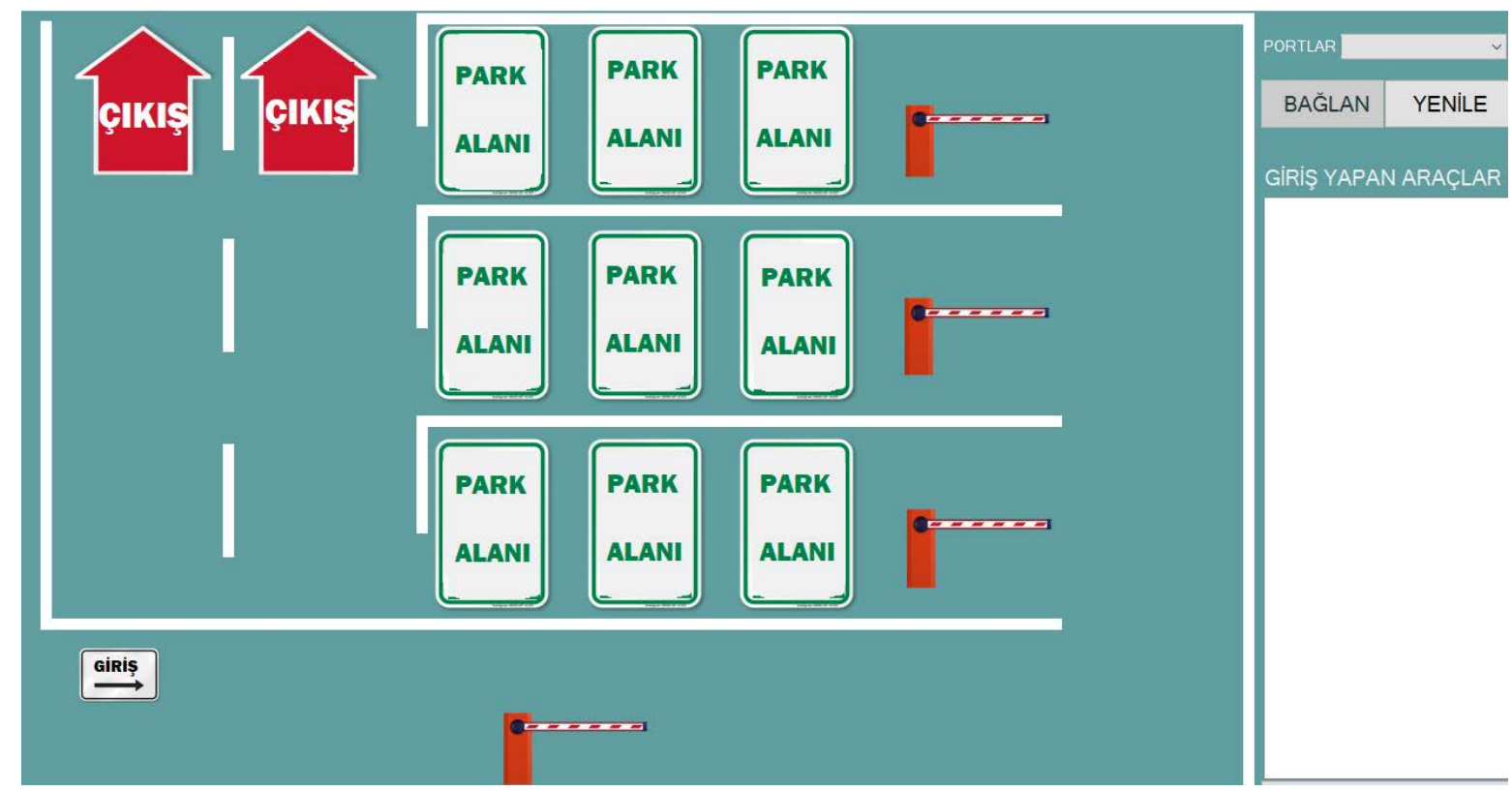

Şekil 17. Arayüz ekranı

\section{Bulgular ve Tartışma}

Projede kullanılan kızılötesi sensör önünde engel olmadığında sinyal ucu pozitif çıkış vermektedir. Sensörün önünde engel bulunmadığında şase-sinyal ucu arası potansiyel farkın 5,4 V ile $6 \mathrm{~V}$ arasında değiştiği, önüne engel konulduğunda ise; şase-sinyal ucu arası potansiyel farkın $0,2 \mathrm{~V}$ 0,4V arası olduğu görülmektedir.

Pozitif gerilimin sistemi çok etkilemediği ancak kızılötesi sensörde alıcı ve verici arasına giren engel sonucu gerilimin $0 \mathrm{~V}$ üzerinde olması mikro denetleyici ünitesinin çalışmasında sıklıkla hata yapmasına neden olmaktadır. Bu denemeler ve ölçümler az da olsa gün ışığı olan ortamda yapılmıştır. Aynı deneme ve ölçümler kızılötesi sensör karanlık veya yapay 1şık altında çalışken yapıldığında sinyal çıkış geriliminin sıfıra çok yaklaştı̆̆ı ve sistemin kararlı çalıştı̆̆ı test edilmiştir. Ayrıca kızılötesi sensör alıcı ve verici ünitesine ışık sızdırmayacak kılıf uygulaması yapılmasının gün ışından olan etkilenmeyi azaltacağı tezinden yola çıkılarak yapılan testlerde sensörün yapısı nedeniyle bunun teknik açıdan mümkün olamayacağı görülmüştür. $\mathrm{Bu}$ nedenle bu sensörden yaklaşık 5 kat daha maliyetli kılıf içinde çalışan MZ-80 kodlu başka bir sensör kullanılmıştır. Sensör aynı çalışma prensibi ile çalıştığı halde alıcı ve verici ledlerin kılıf içine alınmış olması sebebiyle gün 1şı̆̆ından etkilenme en aza indirilmiş durumdadır. Önüne engel geldiğinde tam olarak sinyal şase arası $0 \mathrm{~V}$ okunabilmektedir. 
Özellikle açık otoparklarda kullanılacaksa günışı̆̆ı etkisinin göz önünde bulundurulması gerektiği ortaya çıkmaktadır. Ancak kapalı otoparklarda gün ışığı olmayacağı ve maliyeti gereksiz şekilde arttırmamak için bu sensörün kullanılmasına gerek yoktur.

Otopark doluluk gösterge lambaları yerine kullanılan ledlerin çok güç sarf etmediği düşünülerek beslemeleri direkt Arduino MEGA2560 üzerinden yapıldığında çeşitli sistem sorunları (yer seçme işleminin bozulması, sönük yanma, gömülü sistem üzerinde her işlem sonrası resetleme işlemi yapılması gerektiği) ortaya çıkmaktadır. Bu nedenle doluluk lambalarını temsil eden led sistemi için ayrı kızılötesi sensörler ve her otopark alanı için ayrı röle kullanılması sonucu daha başarılı sonuçlar elde edilmiştir.

Bu büyüklükte akıllı otopark modelinde otopark doluluk gösterge sisteminde kullanılacak güç kaynağı en az 5V 900mA olduğunda yani yaklaşık 5V/5W olduğunda düzgün bir çalışma sergilemektedir. Daha az akım sağlayan güç kaynakları gösterge ledlerinde sönük yanmaya veya 1şık verememesine sebep olmaktadır. Gerçek bir otopark boyutu düşünülecek olursa çıkış gerilimi de LED’lerin besleme gerilimi ve gerilim düşümleri dikkate alınarak hesap edilmelidir.

Sinyal iletimi özellikle ekranlı çok telli sinyal kabloları ile iletilirse manyetik dış etkiler sıfıra yaklaşacaktır. 0,22 $\mathrm{mm}^{2}$ ekranlı çok telli ve 3 damarlı sinyal kablosu özellikle sinyali 12 m’ye kadar 0,3V gerilim düşümü ile iletebilmektedir. Bu gerilim düşümü de devrenin çalışmasına herhangi bir etki etmeyecek seviyededir. Ancak bu uzunluğun üzerinde daha yüksek kesitli iletkenlere ihtiyaç duyulacağı açıktır. Sistemin ilk araç kabul işlemi için başka bir gömülü sistem kullanılırsa yani araç kabul ve yönlendirme ve yerleştirme sistemleri ayrılırsa, bekleme süresi daha kısalacaktır.

\section{Sonuçlar ve Öneriler}

Eserde, Arduino platformu kullanılarak RFID okuyucu ünitesi, kızı̈ötesi sensörler ve servo motorlar kullanılarak, kontrol edilen 3 bölümlü 9 araçlık bir otoparkın insansız otomatik kontrolü sağlanmıştır. Daha çok bölmeli otoparklar için daha fazla sayıda mikro denetleyici kullanmak gerekebilir. Yapılan modelde sisteme temassız müdahale edilmeden devamlılık sağlanmıştır. Ancak girişte kullanılan tanımlama sistemi, tamamıyla otopark seçim sisteminden ayrılırsa yani ayrı bir mikro denetleyici kullanılırsa yeni gelen araçların da kabulü daha hızlı gerçekleşebilir. Otopark içerisindeki yön levhaları ve bağımsız bölüm doluluk gösterge ledleri sayesinde araçların park etme süreleri kısaltılmıştır. Ancak doluluk gösterici aydınlatmaların mikro denetleyici dışında sadece sensör ve röle sistemiyle kontrolü daha kararlı bir çalışma sağlayacaktır. Kızılötesi sensörler ve mikro denetleyici ile bariyerlerin kontrolü sağlanmıştır. Oluşturulmuş olan ara yüz ve yazılım ile otopark girdi ve çıktıları kayıt altına alınmıştır. 
Sistem esnek bir yapıya sahiptir. Başka alanlarda da kullanılabilecek şekilde tasarım geliştirmesine açıktır. Geliştirilmiş olan ara yüz ile araç takibi yapılabilmektedir. Ayrıca sistem daha çok işlev görevi aktarılıp geliştirilebilir. Daha geniş ve büyük yerler için kullanımı sağlanabilir. Yüz tanıma ve plaka tanımlama sistemleri de eklenerek güvenlik seviyesi arttırılabilir.

\section{Teşekkür}

2209-A Üniversite Öğrencileri Araştırma Projeleri Destekleme Programı 13.03.2020 tarihinde başlayan 1919B011903536 başvuru numaralı ‘Akıllı Otopark Sistemi’ başlıklı projeye desteklerinden dolayı Türkiye Bilimsel ve Teknolojik Araştırma Kurumu (TUBİTAK) BİDEB birimine desteklerinden dolayı teşekkür ederiz.

\section{Kaynaklar}

Bhuptani, M. and Moradpour, S. (2005). RFID Field Guide:Deploying Radio Frequency Identification Systems, Sun Microsystems Press, New Jersey.

Chen, N-K., Chen, J-L., Chang,(2008), T9-H., Lu, H-F.,Reliable ALE middleware for RFID network applications, Wiley InterScience

E. Eckermann (2001) World History of the Automobile.

Harwey LEHPAMER,(2008), RFID Design Principles, Artech House Microwave Library, United States of America

JHA A. R. ,(2000), Infrared Technology Applications to Electrooptics Photonic Devices and Sensors, John Wiley \& Sons, Inc, Canada.

Roberts,C.M,(2006) ,Radio Frequency Identificaiton (RFID),Computers\&security, pp 18-36.

Saatçioğlu,Y (2006),RFID Fırsatlar, Engeller ve Örnek uygulamaları

SEN.P.C.,2012,Principles of Electric Machines and Power Electronic, Wiley, Ontario, Canada

Syed A,Ilyas M.,(2008), RFID Handbook Applications, Technology,Security, and Privacy, CRC Press

Want R, (2006), An Introduction to RFID Technology, IEEE Pervasive Computing Intel Research, Santa Clara.

Warren J.,David, Adams J.,Molle H,(2014), Arduino Robotic, Apress. 